\title{
QuestionnAIRE ResPONSE
}

$\mathrm{T}_{\mathrm{H}}$ HE APRIL ISSUE(Vol. 3, No. 1) included a questionnaire soliciting your appraisal of Oceanography magazine. We felt that, after five issues, it was time to evaluate our progress and anticipate course corrections. As of September 1, 1990, 246 questionnaires have been returned, a gratifying response representing about ten percent of our membership. The questions concerning the magazine were grouped in two categories: the first requested evaluations of specific sections or departments, and the second asked for opinions about style and design. Summary results, expressed in percent of the total number of responses to each question, are shown here.

The results support the original concept, which was to publish carefully written, concise articles representing the breadth of

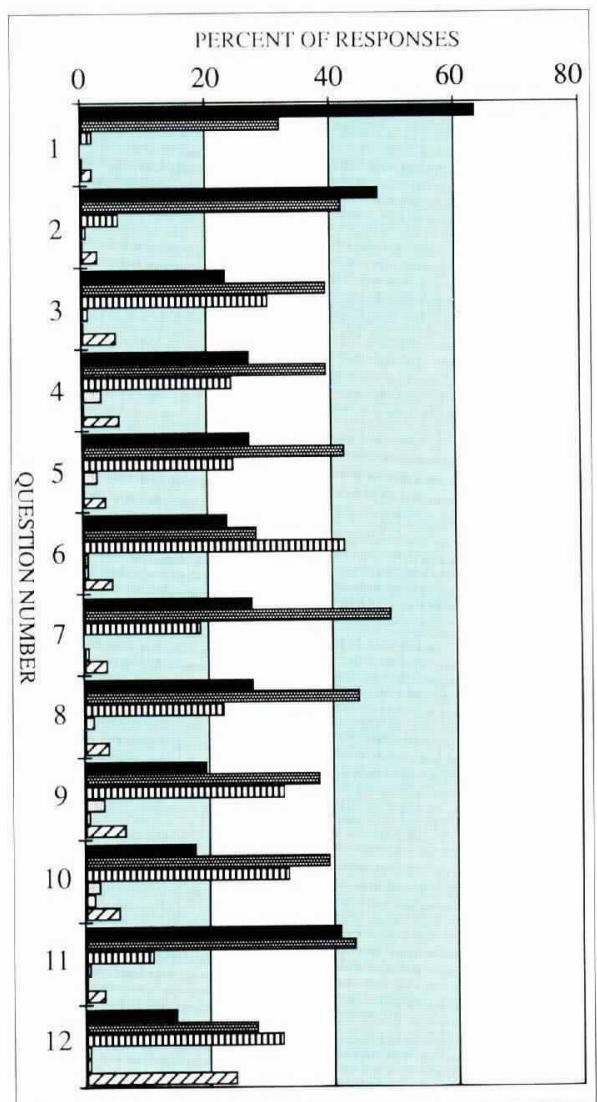

\section{Section/Department}

Strongly Approve

眀 Like

III Neutral

国 Dislike

Strongly Disapprove

$\square$ No Answer ocean sciences, using the format of a magazine as opposed to a newsletter. It is clear that you strongly approve of the use of color reproduction when it enhances the science, and you appreciate the appropriateness of moderate amounts of advertising to help defray costs.

There is broad approval for the specific sections of the magazine, with very few strongly negative responses. However, there is also a range of preferences apparent, and it is clear that some sections are perceived to be more useful than others. As expected, the feature articles and more compact reviewand-comment pieces received your highest ratings, which reflects the magazine's primary function as a medium for scientific exchange. You gave lower marks to the sections dealing with services and facilities, book reviews, society activities, and-perhaps most surprising - students. A relatively large fraction of respondents were uncertain about 'Omega' (a necrology) and gave no opinion on this section.

Wealsoreceived many written comments, some laudatory, a few stinging, most constructive, all appreciated. Space doesn't permit quoting from the list, but a few general themes stand out. First, you pointed out that we haven't done a very good job representing geological oceanography, an appreciated shortcoming that we are diligently working to correct, as this issue and the next will hopefully indicate. You also reminded us that two issues per year can hardly be called punctual publication, and we are painfully aware of this limitation. The reality is that magazine production has been inhibited by

1-Feature articles; 2-Review \& Comment pieces; 3-Society Soundings; 4-Meetings \& Workshops; 5-Calendar of Meetings; 6Studentia; 7-Editorials; 8-Letters; 9-Books \& Videos; 10-Services \& Facilities; 11 - Historical pieces; 12 - Omega. 13-Maintain quality magazine format even at extra cost; 14 Replace magazine with cheaper newsletter; $15-$ Accept a small amount of advertising to defray costs; 16- Sell as much ad space as possible to keep costs down; 17-Use color reproduction when it enhances the science; 18 - Avoid the use of color to minimize the costs; 19 - The breadth and scope of science is about right; 20 - Continue to emphasize short review articles; 21-Publish longer, more extensive articles. lean budgets and a minimal staff. As described elsewhere in this issue, the Society is making changes that may speed up production in the near future. Finally, some of you expressed appreciation for our effort to include in each issue at least one article written in a style accessible to undergraduate, junior college, or high school honors students.

We hear the message to continue to publish good science and good writing in a quality magazine format, but with less emphasis on what might be called peripheral activities. We will do this. In a few years, and regularly thereafter, the waters will again be tested. The basic idea, laid out at the beginning, is that the helmsman of this vessel serves at the pleasure of the crew, and not the other way around. - DAB $\square$

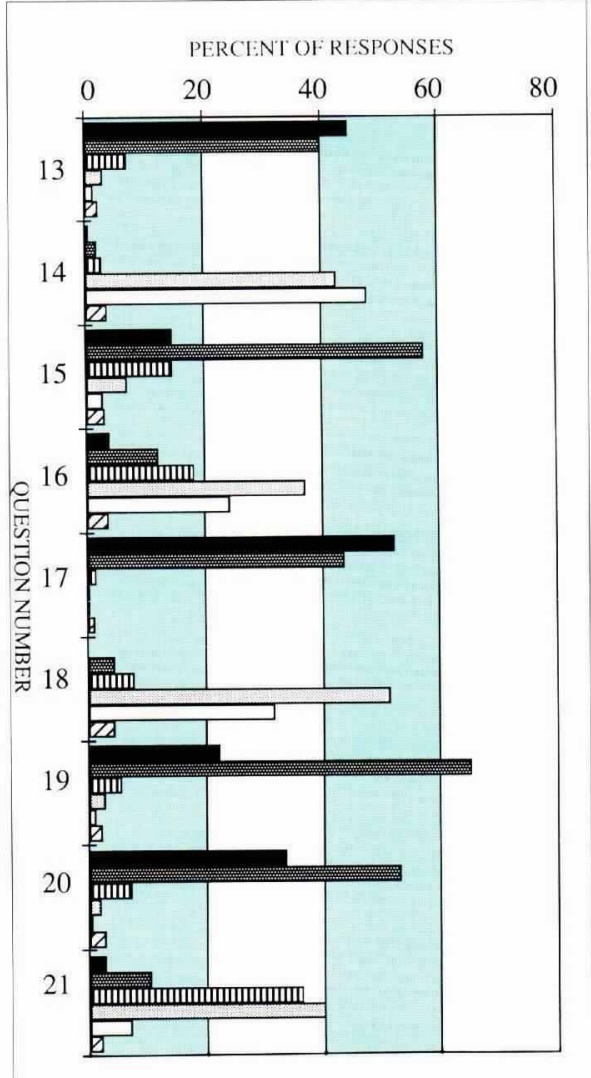

Layout/Design/Concept

Strongly Agree

䀠 Agree

III Neutral

国 Disagree

Strongly Disagree

No Answer 